Diabetologia 8, 236-243 (1972)

(C) by Springer-Verlag 1972

\title{
Metabolic Changes in the Islets of Langerhans in Relationship to the Onset of Diabetes Mellitus*
}

\author{
K. W. Taylor \\ The University of Sussex, Dept. of Biochemistry, School of Brighton, Brighton/Sussex
}

Received: March 9, 1972, accepted: March 24, 1972

Key words: Islets, metabolic changes, diabetes.

This lecture will be concerned with the possible causes of diabetes and how far they may be explicable in biochemical terms. A major question which has to be asked is how does the complex interplay of environment and hereditary influence its onset? At the time Banting discovered insulin, 50 years ago, it was believed that diabetes was a simple endocrine deficiency syndrome, akin to Addison's Disease or myxoedma, to be treated and controlled by insulin. Later this view had to be modified when it was realised that certain other hormones, notably growth hormone [47] and steroids could worsen diabetes or even induce it. Views of diabetes have changed yet again. It is currently thought that diabetes is an expression primarily of some defect in insulin secretion or synthesis, though antagonism to insulin mediated through the pituitary or adrenals may also play a supportive role in onset.

\section{Biochemical characteristics of endocrine cells}

It is now thought that many secretory processes take place by a common mechanism. This is the case for salivary glands, the cells of the gastric mucosa, as well as for endocrine glands such as the pituitary or islets of Langerhans. The basic process of secretion involves peptide synthesis, the translocation of newly synthesised protein to an internal packaging site, and concentration of the hormone in granules. The granules are then discharged by a signal from either a nervous or chemical stimulus. The process of granule formation affords a means of storing a hormone. However, in some endocrine glands, if granules are produced in excessive quantities, they may be destroyed by the intracellular bodies termed lysozomes.

In the case of the beta cell, there are important variations in this process and what distinguishes the beta cells of the islets of Langerhans from other secretory glands is their peculiar dependence on, and

* 22nd Banting Memorial lecture of the British Diabetes Association. (7th Annual Meeting of the European Association for the Study of Diabetes. Southampton 17 th September 1971). sensitivity to the sugar glucose. This is as true for the synthesis of insulin as much as its secretion $[41,35]$. The synthesis of insulin is a multistage process, involving in all species so far examined, the formation of a precursor substance, proinsulin. [41], which is subsequently broken down to produce insulin. The process probably takes place at an early stage of granule formation. The enzymes responsible for the conversion which in mammals have the properties of trypsin and a carboxyepeptidase are now the objects of intensive study.

\section{Secretion of insulin}

The nature of the complex processes by which the stored hormone is extruded is now also the object of considerable debate. In fact until the morphological processes of granule extrusion can be translated into biochemical terms, they are unlikely to be completely understood.

Secretion is thought to involve the movement of granules to the periphery of the cell, where they are discharged [24]. Further important evidence for this process was obtained when the passage of labelled newly synthesised insulin was studied through the beta cell by electron microscopic radioautography [20]. It is now usual to suppose that the progress of the granules is guided through a microtubular system to the cell exterior. However, such a complex series of intracellular changes is likely to involve a highly sophisticated pattern of biochemical events.

It is easiest to conceive of these events as two separate linked activities. In the first of these, glucose or an amino acid for example produces a signal. In the second phase the signal has to be interpreted into a message which causes granules to move and be discharged. It is perhaps easiest to deal with the last system first, since it seems common to many types of secretory tissue.

The essential requirements for the last phase of secretion would appear to be the presence of ionised calcium and of the second messenger substance, cyclic AMP. Several groups of workers have established that insulin secretion was associated with a need for 
the presence of ionised calcium $[16,18,31]$. More recently the important work of Malaisse and his associates has established that insulin secretion by glucose and other secretory agents is accompanied by depressed calcium release by $B$ cells [28].

If a calcium-cyclic $A M P$ activated system is responsible for the final stage of secretion, how is it that in the beta cell of the islets of Langerhans, the system becomes activated by agents such as glucose?

There are broadly two possibilities. Glucose could be metabolished to a compound which serves as an activator material. Alternatively, it might interact with a membrane [29], inducing perhaps a change in the conformational state of the membrane, to facilitate release. At present most opinion favours the necessity for glucose to be metabolised, for at least part, if not

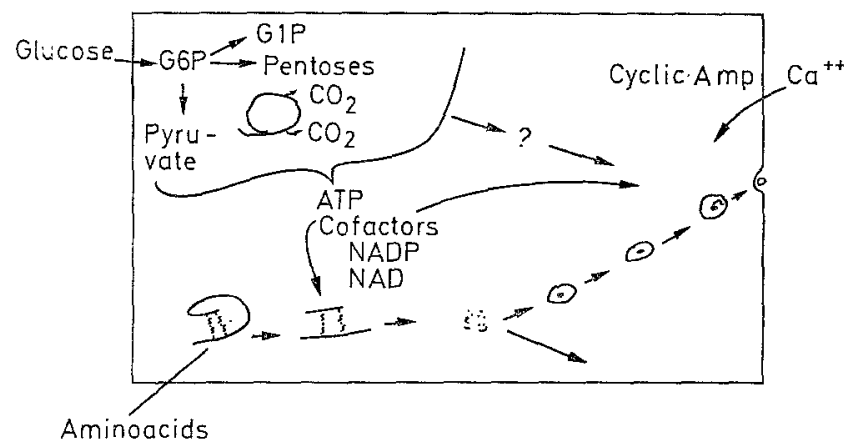

Fig. 1. Metabolism of islets in relation to the insulin release process

the whole, of the secretory cycle. A scheme of the metabolic changes known to take place in islets is shown in Fig. 1.

On this theory, glucose is first metabolised to glucose-6-phosphate, and further metabolism of this substance will give rise to another metabolite which triggers release. Candidates for this have been numerous. They include intermediates in glycolysis $[19,13]$, the pentose phosphate pathway, $[33,34]$ and more recently, levels of pyridine nucleotides, such as NAD [10] which may be especially significant for secretion and its maintenance. It is quite likely, however, that for a process as complex as secretion, several metabolites may be important.

\section{Control of secretion}

If metabolism of glucose is important, control of this process may take place at the level of glucose phosphorylation and important and extensive studies of the enzymes responsible have been made by P.J. Randle's group at Bristol [2]. At the other end of the secretory sequence, control may also be exerted at the level of cyclic AMP levels. Thus glucagon is known to increase cyclic AMP levels in islets; probably the sulphonylureas are effective through this mechanism by a direct inhibitory effect on the diesterase enzymes responsible for cyclic AMP breakdown [15]. Conversely, levels of cyclic AMP are reduced by diazoxide and adrenaline, two agents which are known to block secretion [32]. One naturally occurring substance the sugar mannoheptulose, - blocks secretion by interfering with glucose phosphorylation.

None of these substances which block secretion seems, however, to be associated with the pathogenesis of diabetes in man, with the possible exception of adrenaline which is responsible for the reduced glucose tolerance seen in catechol amine producing tumours.

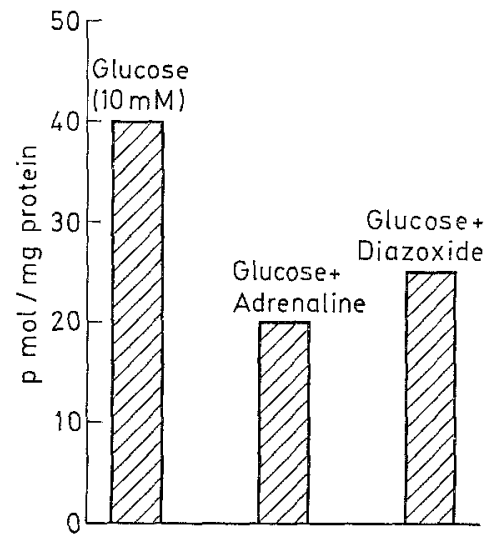

Fig. 2. Effect of glucose, adrenaline and diazoxide on cyclic AMP accumulation in isolated islets of Langerhans. (Data of Montague and Cooke [32]. Ordinate: Levels of cyclic $3^{\prime} 5^{\prime}$ AMP in p.mol/mg protein

\section{Physiological regulation of secretion}

I would next like to deal with the way in which the secretory sequence of events controlled physiologically. How does it respond for example to an additional need for insulin in conditions such as pregnancy or obesity?

\section{Islet changes in pregnancy}

That there is an increased need for insulin in pregnancy is well established. Thus, the insulin requirements of diabetics, dependent on insulin, may be greatly increased towards the end of pregnancy, as is well known [40, 7, 21]. Moreover, insulin secretion in response to glucose or tolbutamide, is exaggerated in the pregnant state. This is despite a glucose tolerance which is essentially unchanged from normal, implying some degree of insulin antagonism. Pregnancy can therefore be regarded as a condition in which the beta cells are abnormally stressed. This is well shown in some experiments recently performed in our laboratory on islets removed from pregnant rats.

When such islets taken from 18-day pregnants rats are incubated with glucose there is a much greater secretion of insulin than in normal female rats (Fig. 3). The curve relating output of insulin to glucose con- 
centration is also markedly different, suggesting that the homeostatic mechanism has been significantly altered. Pregnancy, therefore, directly affects the islet increasing its responsiveness to glucose. Perhaps the effect is on the cyclic AMP controlled part of the secretory sequence. The effect might be an endocrine one, mediated perhaps through placental lactogen, or the steroid hormones, or both in combination.

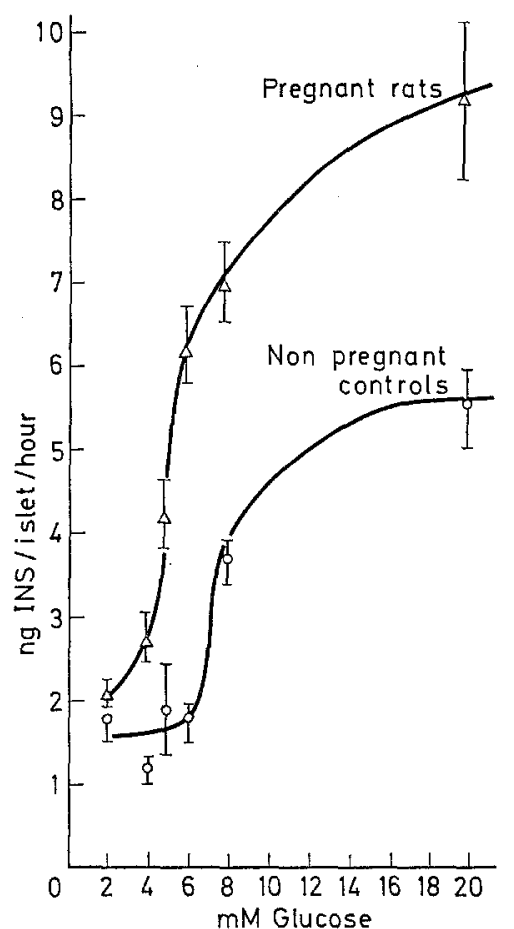

Fig. 3. Effects of glucose concentration on insulin release from isolated islets of Langerhans derived from pregnant rats. Ordinate: Insulin (ng/islet/h) 1, 2, 3, 4, 5, 6, 7, $8,9,10$. Abscissa: Glucose mM. 2, 4, 6, 8, 10, 12, 14, 16, 18,20

A similar direct effect on the islet may also be seen in obesity, and after growth hormone treatment in man or animals [28]. It is also seen in the face of the excessive endogenous growth hormone production associated with acromegaly [38, 41]. There is evidence, moreover, for increased rates of insulin synthesis, after treatment of animals with growth hormone [43] or placental lactogen [30]. Clearly, therefore, any failure in the secretory sequence may make the islet incapable of dealing effectively with the extra demands of a situation like pregnancy or obesity.

\section{The clinical pattern of diabetes}

I have so far dealt at some length with the islets of Langerhans and the nature of the processes leading to the secretion of insulin. It is now time to discuss the clinical pattern of the disease in relation to possible metabolic changes on the islet.
It is of course only a minority of diabetics who present, with the symptom of severe insulin deficiency, characterised by severe weight loss, hyperglycaemia and ketosis indistinguisable in all essentials from experimental diabetes due to beta cell poisons like alloxan. Usually such patients are young, but as has been emphasised by others, the condition may occur at any age. Blood insulin, as R.D. Lawrence first noted, is low as is insulin in the pancreas, particularly in the male. How does such a disturbance arise? The suddenness of the onset, and the lack of a family history in such cases militates against the operation of a genetic factor by itself.

The operation of some toxic or poisonous factor at some point in the secretory cycle is also a possibility. Obvious candidates might be alloxan or agents such as streptozotocin, which are known to cause complete destruction of the beta cells, although as has been discussed elsewhere, there is no convincing evidence for the presence of alloxan or its metabolites in the body fluids in early diabetes. Sulphydryl inhibitors derived from dietary mustard oils such as allyl isothiocyanate have also been suggested as diabetogenic agents by South African workers [8] though the type of diabetes which might be associated with their ingestion is neither severe nor sudden in onset. It is also true that cytotoxins of the alloxan or streptozotocin type are not entirely specific for beta cells and careful examination of tissues ought to reveal a more generalised cytological disturbance due to them. Pathologists have not noticed this in tissues taken from patients with early diabetes. If then there were some toxic agent which gave rise to acute diabetes, it would have to be remarkably selective in its effects.

\section{Pancreatitis and diabetes}

In England, acute pancreatitis is only rarely associated with a fulminating diabetes, although a milder form of diabetes may be associated with the chronic form of the disease. In South Africa, and in this country, there may be definite impairment of the ability to secrete insulin in response to glucose following pancreatitis, but this is not sufficient to account for classical severe diabetes.

We are forced rather to consider acute diabetes as a disease affecting predominantly the islets of Langerhans rather than the pancreatic acinar tissue generally. This is also borne out by the histological studies of LeCompte 1958 [25, 26], and Gepts 1965 [14], emphasising lymphocytic infiltration of the islets. I now wish to turn to the problem of how such a lesion might arise. The possibility of a viral infection, which could initiate diabetes has recently been the subject of a good deal of speculation, both in this country $[11,12,44]$ as well as by Dr. Craighead and Dr. Steinke in the United States. I shall briefly review some of the evidence for this, although I wish to emphasise yet again that the 
evidence which is at present before us for a viral origin for diabetes is at best suggestive rather than conclusive.

First of all, there is the evidence derived from viral diabetes in animals. In two instances in animals a viral infection appears to be associated with a typical insulin deficient diabetes. This was so for diabetes associated with an outbreak of foot and mouth disease in cattle, [36] as well as in the artificially-induced diabetes from EMC virus in mice [9]. Craighead's work on the diabetes induced by EMC virus in mice is especially interesting since diabetes was induced in one particular strain of animal and the effect was best shown after previous steroid treatment. Blood insulin assay showed that the animals ceased to secrete insulin. Since certain strains of mice seemed more susceptible than others, the experiments may form an interesting parallel with the interplay of genetic, hormonal and other factors in the induction of diabetes in man. However, there is no evidence that EMC virus is a causal agent in human diabetes.

The approach in man was initially made by ourselves by looking at the seasonal incidence of diabetes. When this was plotted on a monthly basis, covering the 13-year period, 1956-68, the results were as follows. Insulin dependent diabetics with acute onset, and particularly those aged up to 19 years, acquire their diabetes mainly in the later months of the year. The differences between three monthly periods are highly significant, statistically. They confirm some earlier observations made by Adams [1] in the United States in 1926. In later experiments conducted by Dr. Gamble in collaboration with ourselves, and the Birmingham clinic, we set out to examine the antibody titre to various viruses of young ketotic diabetics, shortly after diagnosis, with a view to finding out if recent infection with any of those viruses under test had taken place.

The antibodies tested for included those against mumps, adenovirus, influenza $A$ and $B$, as well as Coxsackies A and B. In this initial study, there was a clear excess of the diabetics who were positive for antibodies against Coxsackie B groups as against controls. There were no significant differences between the diabetics and the controls for antibodies against mumps or other viruses.

Further analysis of the antibody titres using a neutralising test, showed that antibodies were particularly raised in this group to the Coxsackie B 4 antigen at onset, and that the titre of antibody declined in the months following discovery of diabetes. The details of this work have been published elsewhere but I would now like to assess their meaning in more careful terms.

Because an excess of diabetics show antibodies against a virus, this does not mean that that virus must necessarily be the pathogen responsible for it. The organisms have not been found to be excreted by recently diagnosed diabetics, nor have they been discovered in islet tissue. Even if viruses are respon- sible sometimes for diabetes in man, the possibility also exists that more than one virus could be involved. Thus, mumps has occasionally been incriminated as the agent in sporadic cases of diabetes during the last 50 years, though there has never been adequate serological data to prove it. We do not know whether an excess of Coxsackie B4 virus antibodies will always be found in any given year or in any given locality. It is therefore exceptionally important that work on viruses and their relationship to diabetes be continued to give a conclusive answer to this problem.

\section{Non-insulin dependent diabetes}

I have so far dealt with severe diabetes with sudden onset and suggested that this diabetes may be a consequence of some rapidly destructive lesion of the islets of Langerhans. What about those patients whose diabetes is relatively mild, and does not normally require insulin for its control ?

This group forms of course the largest in any British diabetic clinic. It can be divided into those who are overweight, and those who are normal or even underweight. The glucose tolerance and insulin responses of the first - the underweight groups - are shown in Fig. 4. This group is clearly underproducing insulin. Often the error may be corrected by the administration of the sulphonyl-ureas.

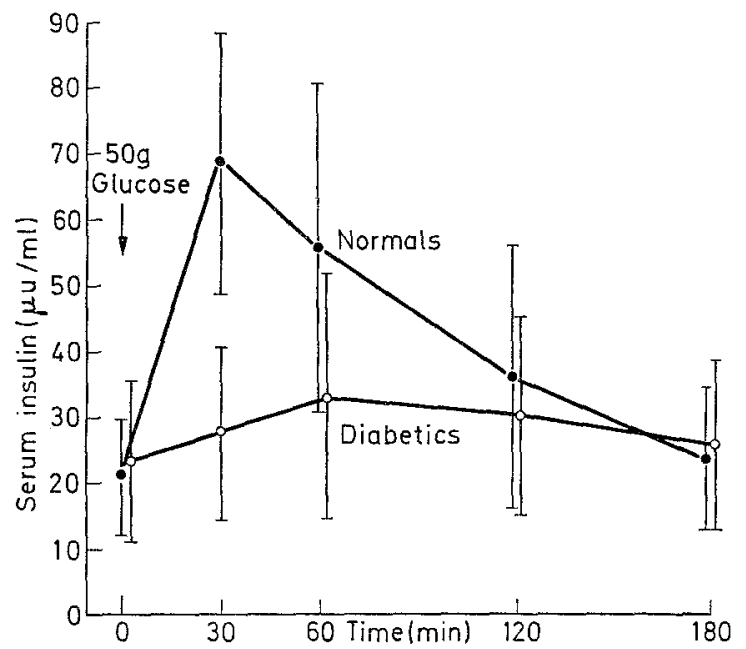

Fig. 4. The insulin response to glucose of mild, underweight diabetic patients. Ordinate: Serum insulin $(\mu \mathrm{u} / \mathrm{ml})$ $10,20,30,40,50,60,70,80,90$. Abscissa: Time in min 0 , $30,60,120,180$

The obese group, however, is rather more of a puzzle. This group, in the untreated state may show very high blood insulin levels. If they produce so much insulin, why then are they diabetic? The seeming paradox was first successfully resolved by Grodsky and his collaborators [17] who showed that these high insulin levels are a necessary function of obesity in 
which there may be gross insulin antagonism. Indeed, high as these levels are, control of glucose levels needs an even higher level of insulin. Thus, as is well known to clinicians, if extra insulin is given to such patients, then their blood sugars are often brought under control. In fact, when attempts are made to relate insulin secretion in such patients to actual blood glucose levels, they are actually seen to be undersecretors [22]. High blood glucose levels in this condition have frequently been ascribed to a delay in initiating insulin secretion. Yet another possible reason for the high blood glucose levels, after oral glucose in these patients, may be the high levels of glucagon in their serum, recently reported by several groups of workers $[3,45]$.

As is well known, the high blood glucose and insulin levels are easily controlled by dietary restriction of carbohydrate, suggesting that under ordinary circumstances, and particularly when the stress of obesity is removed, the islets may function relatively normally.

This effect is not apparently related merely to body weight, as has been shown in elegant experiments in which isocaloric diets of varying composition have been fed to obese subjects. Feeding a high fat diet lowered the ability of the islet to respond to glucose [23]. A high carbohydrate diet is necessary for the expression of hyperinsulinism.

The overall picture in this group of patients is therefore one of failure of the beta cells to adapt to the stress of obesity. A similar failure to adapt to stress, this time the stress of pregnancy, is seen in a group of latent diabetics, whom we studied in the later stages of pregnancy.

In Fig. 5 taken from Dr. Campbell's data, the deterioration in glucose tolerance during the last part of pregnancy is well seen. Also seen is the inadequate insulin response, particularly in the face of considerably elevated blood sugars. Several other groups have also published similar data and there can be no doubt that the worsened tolerance is associated with a primary failure of the islets of Langerhans in this condition. On the assumption that such patients do not secrete enough insulin, or do not secrete it at an appropriate time after glucose, what is the nature of the change in the beta cell which is responsible? At post mortem, the islets of such patients are frequently filled with glycogen. Since gluconeogenesis does not seem significantly to take place in islets, the glycogen must be derived from rapid transformations of glucose involving phosphorylation. If there is any disturbance of the secretory mechanisms in this kind of patient, it seems more likely to involve the later part of the secretory mechanism.

Once again it is tempting to suppose that some extraneous event may have triggered off the change in the islets. Maturity onset diabetes can frequently arise without any family history or obvious genetic background.

\section{The genetic element in diabetes}

The last topic I wish to discuss in detail is the genetic aspect of diabetes. I do not of course have to remind this audience that there is now a large literature on this topic. There is also an impressive body of research on the way in which various kinds of diabetes may be inherited in animals [39]. Clinicians have noted a familial tendency in diabetes for at least four centuries, and it has been suggested that the tendency to diabetes might be inherited as a Mendelian recessive trait by some workers, or as a Mendelian dominant by others.

Most groups of workers have suggested that first degree relatives of diabetics, and twins of diabetics show a lessened ability to secrete insulin in response to glucose. The subject has been discussed at length in the elegant studies of Drs. Cerasi and Luft $[5,6]$ and by work on identical twins.

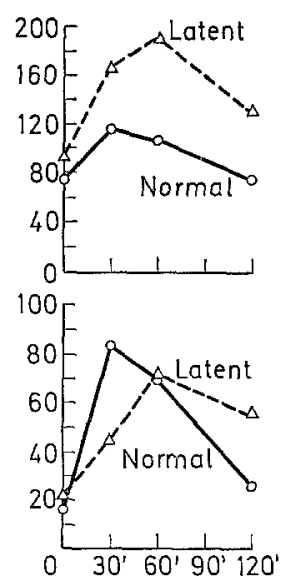

Fig. 5. The insulin response to glucose in pregnancy of latent diabetic patients. Ordinate: (Upper curve) blood glucose $(\mathrm{mg} / 100 \mathrm{ml}) 0,20,40,60,80,100,120,140,160$, 180, 200. Abscissa: Time in min $0,30,60,90,120$. Ordinate: (Lower curve) serum insulin ( $\mu \mathrm{u} / \mathrm{ml}) 0,10,20,30$, $40,50,60,70,80,100$. Abscissa: Time in min $0,30,60$, 90,120

The results of the work on the twins are summarized in Fig. 6 taken from the data of Pyke and his collaborators [37]. Glucose tolerance and insulin secretion has been compared in 24 apparently unaffected identical twins of diabetics with the results in 50 normal controls. Glucose tolerance shows slight but significant impairment, whereas insulin secretion, even in the face of raised blood glucose levels, is less than normal. The work of Cerasi and Luft has implied it is the earliest phase of the secretory response which is lessened.

The two questions which have to be asked about this abnormal response are firstly, what is its nature, and secondly, what is its clinical significance? It is in fact not very easy to give concrete answers to either of these questions. 
If I might remind you of the chain of events leading to secretion you will see that there are very many theoretical stages (Fig. 1) where the process might be interrupted. It seems unlikely that insulin synthesis is disturbed, say, at the ribosomal level, otherwise, all phases of secretion might be equally diminished throughout a glucose tolerance test. The same argument would also apply to the synthesis of an abnormal insulin differing in amino acid sequence from human insulin. If a delay in the conversion of the precursor, pro-insulin to insulin were the cause, then perhaps more pro-insulin might be found circulating in the serum of diabetic relatives, though this does not seem to be so.

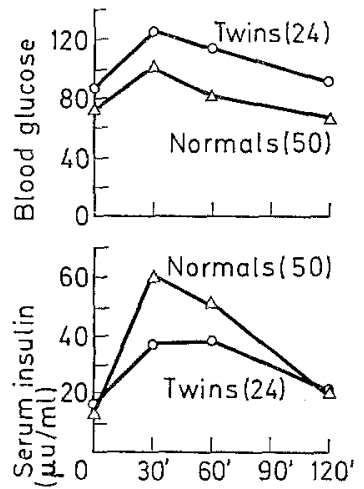

Fig. 6. Serum insulin and glucose in identical twins of diabetics. Ordinate: (Upper curve) blood glucose (mg/ $100 \mathrm{ml}) 0,20,40,60,80,100,120,140$. Abscissa: Time in min $0,30,60,90,120$. Ordinate: (Lower curve) serum insulin $(\mu \mathrm{u} / \mathrm{ml}) 0,10,20,30,40,50,60,70$. Abscissa : Time in $\min 0,30,60,90,120$

It seems much more likely that the secretory mechanism of the beta cell is involved. The two possible points in the secretory sequence which might be affected are its beginning and its end, that is at the kinase level, where glucose is being phosphorylated, or alternatively at the terminal stages with which cyclic AMP is associated. Evidence in favour of the defect involving the last stages of secretion has been put forward by Cerasi. It would also be an important corollary of this scheme that all secretogogues, and not just glucose, which operate through cyclic AMP should exhibit a lessened effectiveness in the close relatives of diabetics. For technical reasons, conclusive evidence about this is at present lacking.

Supposing such a defect exists in the beta cell, we are then faced with the problem of its clinical significance. Does, for example, the possession of this defect in the beta cell, imply that the relatives of diabetics will inevitably acquire diabetes themselves? Data derived from twin studies suggests that there is no inevitable progression of these minor defects to diabetes itself. Indeed, the apparently unaffected twins of known diabetics may exhibit the abnormality over many years without it progressing to frank diabetes.
The next question to be asked is how do those factors such as obesity or pregnancy affect subjects with these minor defects in insulin secretion? From the very limited data which we have available, neither pregnancy nor obesity in the close relatives of diabetics seem by themselves sufficient to induce a state of frank diabetes. In pregnancy in such subjects, the rises in blood sugar are very slight, and are matched. by small additional increases in insulin levels.

I would suggest, therefore, that the onset of frank diabetes requires the intervention of some additional extraneous factor for its full expression and it may be that a genetic factor renders an individual more susceptible to the influence of such an extraneous event.

\section{General Conclusion}

If $\mathrm{I}$ could now summarise some of my comments as in any disease, the interplay of genetic and acquired factors will be decisive in determining the mode of onset, and the diseases' subsequent course. I would like to suggest that some extraneous factor is the main responsible for the induction of diabetes in many instances. This factor may produce in some cases a destructive lesion of the islets of Langerhans, leading to an acute insulin deficient diabetes.

I have discussed possible factors which might induce such a change, and have given some reasons for thinking that viral factors may sometimes be important. I would, however, like to emphasise that the evidence on this is at best tentative, and if viruses are important, then as in animals, more than one type may be involved.

We do not know at present to what extent some toxic or other destructive agent may be responsible for other forms of diabetes, which are less severe in type. I would like to remind this audience, however, that diabetes of lesser severity seems to be associated with some type of defective insulin secretion.

An undoubted genetic element for diabetes also exists. At present this might involve a relatively minor defect in the insulin release mechanism, perhaps in the later stages of the process. However, this defect appears to be widespread within normal populations, and it clearly in itself does not lead to frank diabetes. It may, nevertheless, be an important predisposing factor in some kinds of the disease. Genetic factors might, for example, predispose towards pancreatic damage.

If some acquired factor produces islet damage this might remain minimal or undetected, unless the beta cells are subjected to unusual stress, as for example in pregnancy, obesity or acromegaly. Perhaps, too, the enteric hormones may play some role in beta cell stimulation. A gain in weight may prove the coup de grace to an already afflicted pancreas.

Finally, at this stage of development of the subject, I am only too well aware that what I have said is 
speculative and based on little concrete scientific evidence. I take my excuse, however, from Claude Bernard [4] who said "We must be able to attack questions, even at the risk of going wrong".

\section{References}

1. Adams, S.E.: The seasonal variation in the onset of acute diabetes; the age and sex factors in 1000 diabetic patients. Arch. intern. Med. 37, 861 (1926).

2. Ashcroft, S.J.H., Hedeskov, Randle, P.J.: Glucose metabolism in mouse pancreatic islets. Biochem. J. 118, 43 (1970).

3. Assan, R., Hauteconverture, G., Guillemant, S., Dauchy, F., Brottin, A., Devrot, M.: Evolution de paramètres hormonaux (glucagon, cortisol, hormone somatotrope) et énergétiques (glucose, acids gras, glycerol libre) ans 10 acido-retorer diabetiques graves traitées. Pathol. Biol. 17, 1095 (1969).

4. Bernard, C.: Introduction to the study of experimental medicine, 1865 , p. 40, translated by Greene, H.C., Dover, Publication 1957.

5. Cerasi, E., Luft, R.: The plasma insulin response to glucose infusion in healthy subjects and diabetes mellitus. Acta ondoc. (Kbh.) 55, 278-324 (1967).

6. Cerasi, E., Luft, R.: "What is inherited - What is added". Hypothesis for the pathogenesis of Diabetes Mellitus. Diabetes 16, 615-627 (1967).

7. Campbell, N., Pyke, D.A., Taylor, K.W.: Oral glucose tests in pregnant women with potential diabetes, latent diabetes and glycosuria. J. Obstet. Gynec. Brit. Emp. 78, 498 (1971).

8. Camploell, G.D., McKechnie, J.: Recent observations on Zulu and Natal indian diabetics in Durban. S.A. Med. J. 35, 1008-1011.

9. Craighead, J.E., McLane, M.F.: Diabetes mellitus induction in mice by encephalomyocarditis virus. Science 162, 913 (1968).

10. Deery, D.J., Coleman, T.J., Taylor, K.W.: Effect of azaserine on insulin release, in vitro. Biochem. J. 124, $65 \mathrm{P}$ (1971).

11. Gamble, D.R., Taylor, K.W.: Seasonal incidence of diabetes mellitus. Brit. Med. J. 3, 63 (1969).

12. - Kinsley, M.I., Fitzgerald, M.G., Bolton, R., Taylor, K.W.: Viral antibodies in diabetes mellitus. Brit. med. J. 3, 627 (1969).

13. Georg, R.H., Sussman, K.E., Wayne-Leitner, J., Kirsch, W.M.: Inhibition of glucose and tolbutamide induced insulin release by iodoactate and antimycin, Endocrinology 89, 169-176 (1971).

14. Gepts, W.: The cytological pathology of the islets of Langerhans in juvenile diabetes. Structure and metabolism of the pancreatic islets, p. 513-519. Ed. by Brolin, S.E., Hellman, B., Knutson, H. Pergamon Press (1964)

15. Goldfine, I.D., Perlman, R., Roth, T.: Inhibition of cyclic $3^{\prime} 5^{\prime}$ AMP diesterase in islet cells and other tissues by tolbutamide. Nature 234, 295-297 (1971).

16. Grodsky, G.M., Bennett, L.L.: Aotion requirement for insulin secretion in isolated perfused pancreas. Diabetes 15, 910-913 (1966).

17. - Karam, J.H., Pavlatos, F.C., Forsham, F.H.: Serum-insulin response to glucose in prediabetic subjects. Lancet $1965 \mathrm{I}, 290$.

18. Hales, C.N., Milner, R.D.G.: Cations and the secretion of insulin from rabbit pancreas, in vitro. J. Physiol. 199, 177-187 (1968).

19. Hellman, B., Idahl, L.A., Danielsson, A.: Adenosine triphosphate levels of mammalian pancreatic $B$ cells, after stimulation with glucose and hypoclycaemic sulphoryl. Diabetes 18, 509 (1969).
20. Howell, S.L., Kostioneivsky, M., Lacy, P.E.: Beta granule formation in isolated islets of Langerhans. J. cell Biology 42, 695-705 (1969).

21. Kalkoff, D.F., Schalch, D.S., Walker, L., Beck, P., Kipnis, D.M., Daughaday, W.H.: Diabetogenic factors associated with pregnancy. Trans. Ass. Amer. Phyens. 77, 270-279 (1964).

22. Kipnis, D.M., Perley, M.: Plasma insulin responses to glucose and tolbutamide of normal weight and obese diabetic and non-diabetic subjects. Diabetes 15, 867874 (1966).

23. - In "The Pathogenesis of Diabetes" Cerasi, E., Luft, R. Ed. in Nobel Symposium 13, p. 53. Almquist, Wiksell, Stockholm (1969).

24. Lacy, P.E.: Functional morphology of the islet cells in "The Pathogenesis of Diabetes", Cerasi, E., Luft, R.: Nobel Symposium 13, p. 333-335. Almquist \& Wiksell, Stockholm (1969).

25. Lecompte, P.M.: Insulinitis in early juvenile diabetics. Arch. Path. 66, 45D (1958).

26. - Legg, M.A.: Insulinitis (Lymphocytic infiltration of pancreatic islets), in Maturity Onset Diabetics. Dia. betes 20, Supplement-Abstracts of Amet.-Diabetes Assen. 341 (1971).

27. Malaisse-Lagne, F., Malaisse, W.J.: Stimulation coupling of glucose-induced insulin release III. Uptake of ${ }^{45} \mathrm{Ca}$ by isolated islets of Langerhans. Endocrino$\log _{y} 88,72-80$ (1971).

28. Malaisse, W.J., Malaisse-Lagae, F., King, S., Wright, P.H.: Effect of growth hormone on insulin secretion. Amer. J. Physiol. 215, 423-442 (1968).

29. Matschinsky, F.M., Ellerman, J.E., Kozanowski, J., Kotler-Brajtburg, J., Landgrat, R., Fertel, R.: The dual function of glucose in islets of Langerhans. J. biol. Chem. 246, 1007-1011 (1971).

30. Martin, J.M., Friesen, H.: Effect of human placental lactogen on the isolated islets of Langerhans in vitro. Endocrinology 84, 619-621 (1969).

31. Milner, R.D.G., Hales, C.N.: The interaction of various inhibitors and stimuli of insulin release studied with rabbit pancreas, in vitro. Biochem. J. 113, 473-479 (1969).

32. Montague, W., Cooke, J.R.: The role of adenosive $3^{\prime} 5^{\prime}$ cyclic monosulphate in the regulation of insulin re. lease by isolated rat islets of Langerhans. Biochem. J. 122, $115-120(1971)$.

33. - Taylor, K.W.: Pentitols and insulin released by isolated rat islets of Langerhans. Biochem. J. 109, 333-339 (1968).

34. - - Islet cell metabolism during insulin release. Biochem. J. 115, 257-262 (1969).

35. Parry, D.G., Taylor, K.W.: The effect of sugar on incorporation of $\left({ }^{3} \mathrm{H}\right)$ leucine into insulin. Biochem. J. $100,2 \mathrm{c}-4 \mathrm{c}(1966)$.

36. Pedinini, B., Avellini, G., Morettini, B., Comodo, N.: Diabetes mellito post afroso rei bovin. Atti-sec isul Sci. Vet. 16, 443 (1962).

37. Pyke, D.A., Cassar, J., Todd, J., Taylor, K.W.: Glucose tolerance and serum insulin in identical twins of diabetics. Brit. med. J. 4, 649 (1970).

38. Randle, P.J.: Plasma insulin activity in acromegaly. Lancet 1954 I, 441-444.

39. Renold, A.E., Burr, I., Stauffacher, W.: The pathogenesis of diabetes mellitus. Possible usefulness of spontaneous hyperglycaemic syndromes in animals in Nobel Symposium on Pathogenesis of Diabetes. 215231. Almquist and Wiksell, Stockholm (1970).

40. Spellacy, W.M., Goetz, F.C.: Plasma insulin in normal late pregnancy. New England. J. Med. 268, 988 (1.963).

41. Steiner, D.F., Clark, J.L., Nolan, C., Rubenstein, A. H., Margoliash, E., Aten, B., Dyer, P.E.: Proinsulin and the biosynthesis of insulin. Rec. Prog. Formone Res. 25, 207-268 (1969). 
42. Taylor, K.W.: Biosynthesis of insulin. CIBA Symposium on Endocrinology 15, 89 (1964).

43. - Biosynthesis of insulin proceedings of 3rd International Congress of Endocrinology. Ed. by Gual, C., Ebay, F.J.G. in Exerta Media Int. Congress 17-220 (1969).

44. - Gamble, D.R.: Viruses and other factors in the aetiology of diabetes mellitus. Acta Diabetologia Latina, vol. VII, Supplement 1, p. 397-412 (1970).

45. Unger, R.M., Aquilar-Parada-E., Muller, W.A. Eisentraut, A.M.: Studies of pancreatic alpha cell function in normal and diabetic subjects. J. clin. Invest. $49,837(1970)$.
46. Yalow, R.S., Berson, S.A.: Immunoassay of endogenous plasma insulin in man. J. clin. Invest. 39, 1157-1175 (1960).

47. Young, F.G.: Permanent experimental diabetes produced by pituitary (anterior lobe) injections. Lancet II, $372-374$.

Dr. K.W. Taylor

The University of Sussex

Dept. of Biochemistry School of

Brighton

Brighton/Sussex

England 